\title{
Karnali Cable-Stayed Bridge: Development of Finite Element Model and Free Vibration Analysis
}

\author{
Bipin Shrestha
}

East West Engineering Services, Kathmandu, Nepal

Corresponding Email: bipinsh01@gmail.com

\begin{abstract}
This paper describes an analytical investigation on Karnali cable stayed bridge across the Karnali River. The primary objective of the investigation is to develop a three dimensional finite element model capable of representing essential feature of the long span cable-stayed bridge. Various parametric studies on the simple cable-stayed bridge model are performed before the actual development of a complex three dimensional model. Deformed equilibrium configuration due to the dead load is calculated using the cable tension and applied dead loads. Importance of incorporating large displacement geometric nonlinearity during the dead load deformed equilibrium configuration is analyzed .Starting from the deformed equilibrium configuration; modal analysis of the bridge is carried out. Different observed modes are classified based on the dominant modal components. Comparisons of the global modal behavior using the two separate models utilizing different cable modeling techniques are made. Parametric study on effect of cable local vibration and the modeling of deck concrete of the composite deck on overall global modal characteristics is presented.
\end{abstract}

Keywords: Cable stayed-bridge, modal analysis, Finite element model, Three dimensional model, Cable local vibration.

\section{Introduction}

The contemporary cable-stayed bridge is becoming more and more popular and being used where previously a suspension bridge might have been chosen. The increasing popularity of cable-stayed bridges are attributed to, (1) the appealing aesthetics: (2) the full and efficient utilization of structural materials; (3) the increased stiffness over suspension bridges; and (4) the relatively small size of the bridge elements. Rapid progress has been made over the past few decades in the design techniques of cable-stayed bridges; this progress is largely due to the use of advanced computers, the development of new composite sections and materials, and the manufacturing of high strength wires that can be used for cables. Cable-stayed bridges, in which the deck is elastically supported at points along its length by inclined cable stays, are now entering a new era, reaching span lengths of very large proportion, for examples, $890 \mathrm{~m}$ for Tartara Bridge in Japan, $856 \mathrm{~m}$ for Pont de Normandy Bridge in France, and $628 \mathrm{~m}$ for Nancha Bridge in China. There have been several concerns over the use of cable-stayed bridges despite all the advantages. Cable-stayed bridges are apt to look somewhat angular and highly stressed. They are normally sensitive to dynamic loadings such as earthquakes, winds and vehicles. Because of the fact that these long span cable-supported structures constitute complex structural with mainly geometric nonlinearity, it is essential to understand and realistically predict their structural response to these loadings. Accordingly, it is highly desirable in bridge engineering to develop accurate procedures that can lead to a thorough understanding of the static, dynamic, and seismic and wind problems of cable-stayed bridges. The finite element method is currently a common way to perform the non-linear static as well as modal analysis and dynamic response 
analysis under earthquake, wind and vehicle loadings [1-5]. Starting from the knowledge of the structure geometry, the boundary conditions and material properties, the mass, stiffness and damping distribution of the structure are expressed in a matrix form. The success of finite element method application strongly depends on the reliability of the model since many simplifying assumptions are made in modeling the complicated structures, and there are many uncertainties in the material and geometric properties.

In this paper parametric study on Karnali cable stayed bridge is presented to find out its responses to static and dynamic loading. This paper particularly focuses on the development of the complex three-dimensional structural model, with role of various structural idealization of finite element modeling on the static and dynamic response of the bridge.

\section{Bridge Description}

Karnali cable stayed bridge is the first and to date only cable-stayed bridge in Nepal. The bridge site is located about $500 \mathrm{Km}$ west of Kathmandu. The Karnali Bridge is a key structure connecting western Tarei plains of Nepal with rest of the country. Moreover, it also serves as link to reach many western mountains of the country. The bridge has the main span of $325 \mathrm{~m}$ and side span of $175 \mathrm{~m}$ supported on single pylon of $120 \mathrm{~m}$ height above the deck.

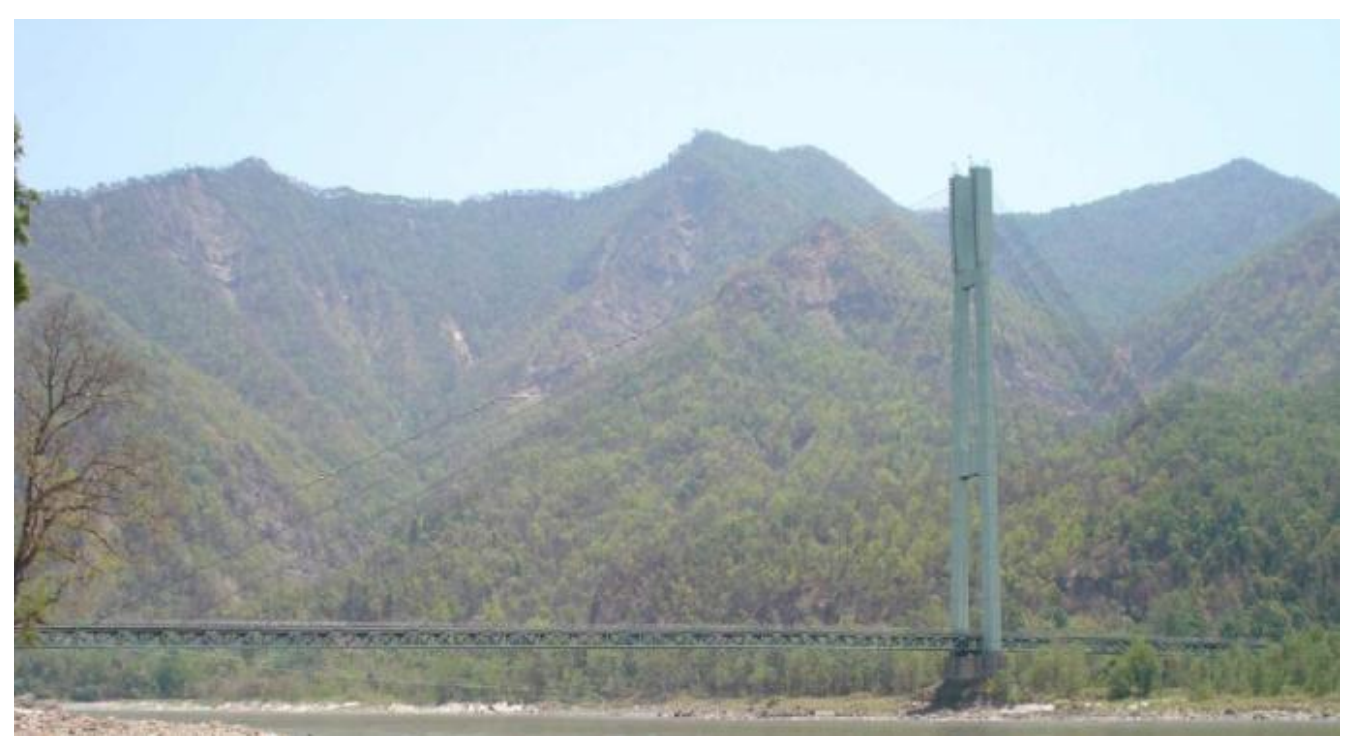

Figure1: Image of Karnali Cable-stayed Bridge stayed

The cables are arranged in two vertical planes with 30 cables in each plane. A modified fan configuration has been adopted for the cables. The stay cables are made of Polyethylene sheathed strands composed of $7 \mathrm{~mm}$ diameter galvanized wires. A composite girder, consisting of $225 \mathrm{~mm}$ concrete slab over $3 \mathrm{~m}$ deep steel truss, has been used. The pylon consists of a hollow stiffened steel section with a height of $120 \mathrm{~m}$ above the bridge deck. The roadway is 11.3 wide, with two traffic lanes. The Karnali cable-stayed bridge was designed by Steinman Boynton Gronquist and Birdsall, New York and the construction was completed by Kawasaki heavy labs of Japan in1993. 


\section{Finite Element Modeling (FEM)}

\section{Discussion on important aspect of modeling}

Creating a realistic three dimensional dynamic finite element model for cable-stayed bridge is not an easy task. Many different modeling strategies are possible. The choice of strategy depends upon skill of an analyst and on the intended application of the model. The accuracy of results of the dynamic analysis obviously depends upon the precision of the FEM. However, extremely large computational effort is required depending on the numbers of degrees of freedom in the model. There is no unique way to conclude that the model developed is the best.

\section{Simplified three dimensional model and full three dimensional model}

Contemporary cable-stayed bridges are complex, efficient and aesthetically pleasing structures which are appearing in various forms. They involve a variety of decks, towers and stay cables that are connected together in different ways. To reduce the degrees of freedom and simplify the dynamic analysis, several simplified three-dimensional finite element models of cable-stayed bridges are developed using elastic beam elements to model the towers and deck, and truss elements to model the cables. The single-girder (spine) model is the earliest three-dimensional finite element model of cable-stayed bridges in structural dynamics.

The parametric bridge deck model with span of $100 \mathrm{~m}$ on each side was developed using a single central spine with offset rigid links to accommodate cable anchor points. The deck stiffness was assigned to the spine, and mass (translational and rotational) was assigned to the spine nodes. This simplified model neglects the floor beam stiffness and girder warping, so it is suitable for a box section girder with relatively large pure torsional stiffness but small warping stiffness. However to increase the accuracy of the model simplified three dimensional modeling approach is inappropriate. A full three dimensional parametric model of the same hypothetical bridge was then developed. Which showed the modeling of the deck is relatively ambiguous by using the simplified beam element model. The adequacy of the simplified models is particularly questionable when representing the bridge deck system in the lateral and torsional vibration. The lateral vibration modes may be distorted to some extent if the deck stiffness equivalence is treated improperly. Relatively large differences of torsional frequencies were also found between two models.

To represent the bridge dynamic behavior well, instead of simplified beam element models, a full three-dimensional finite element model is required with several types of elements such as beam elements, truss elements, shell elements, solid elements and link elements representing different components of cable-stayed bridges. Hence, full three-dimension model is used for the analysis.

\section{Soil structure interaction and Fixed base model}

It is well established fact that the soil that a structure is founded on has a significant effect on the earthquake response of the structure, especially those founded in the soft soil or for very massive, short period structure. Most of the cable-stayed bridges studies cited ignore the soil structure interaction. The references indicate that soil-structure interaction effects may be safely disregarded in well-founded, long-period structures. In this study also the soil-structure interaction has been disregarded. 


\section{Small deformation analysis and Large deformation analysis}

As mentioned earlier nonlinearity of cable-stayed bridges arise from cable sag, large deflection, and axial force-bending moment interaction. With the rapid development of powerful computers and the concept of matrix analysis on Non-linear problems, there is now no difficulty in performing the geometrical nonlinear analysis of cable-stayed bridges. Main problem with including the large deformation geometrical nonlinearity in the seismic analysis is long analysis period. Many studies [1, 2, 9] have shown that small deformation analysis is adequate to calculate the equilibrium configuration of cable-stayed bridges under dead load and seismic load. Hence a comparative study including the large deformation geometric nonlinearity is presented with case neglecting it.

\section{Dead load deformed equilibrium condition}

The dead load deformed equilibrium condition of cable-stayed bridges is the equilibrium condition due to dead load and tension forces in the cables. The Subsequent modal analysis and nonlinear time history analysis should start by considering dead load deformed equilibrium condition. In this study the dead load deformed equilibrium condition of the finite element model the final displacement of the deck should be identical to the as built drawing of the bridge. This can be realized by manipulating the initial tension force in each stay cable elements. The design cable tensions are first applied to the each cable and the static nonlinear analysis under dead load shall be carried out to compare the calculated deck alignment with the measured deck alignment. The cable tension then is adjusted until the best match is achieved.

\section{Concrete slab in the composite deck}

Simple beam element model with lumped mass at each beam node of the deck representing the concrete deck slab significantly underestimates the transverse and torsional stiffness of the deck [6]. Though the concrete slab found have smaller effect on the vertical bending modes of the bridge deck its influence in nature of vibration in bridges transverse and torsional mode is significant. Hence to accurately represent the bridge dynamic behavior the deck slab is modeled as the shell element.

Parametric study is however presented to find the effect of modeling of deck concrete on the response the bridge deck.

\section{Development of Finite Element model}

A 3-D FEM of the Karnali cable-stayed bridge was developed using SAP2000 structural analysis software, as shown in Fig. 2 the Bridge is modeled based on the geometries and material data from as-built drawings. The FEM employed frame elements for steel girders, floor beams and the center strut connecting any two adjacent floor beams. The main components of the bridge towers and pier were represented by non-prismatic frame elements. The $228 \mathrm{~mm}$ thick precast concrete panel/slab supported by the steel girders was modeled with shell elements. In the model, cables were modeled using a straight chord element. Sagging of the inclined cables is considered using equivalent modulus of elasticity as suggested by Ernst (1965).

$$
\mathbf{E e q}=\frac{E}{1+\frac{(\mathrm{wl})^{2} \mathrm{AE}}{12 \mathrm{~T}^{3}}}
$$


Where,

Eeq = equivalent elastic modulus of inclined cable,

$\mathrm{E}=$ cable material elastic modulus,

$\mathrm{L}=$ horizontal projected length of the cable,

$\mathrm{W}=$ weight per unit length of the cable,

$\mathrm{T}=$ tension at dead load.

A full 3-D model was hence developed using 1005 joints,2006 frame elements, 495 shell elements, and 2 rigid link, 4 solid elements for a total of 5995 degrees of freedom. For a detailed description of the model refer Shrestha [9].

\section{Material cross section property}

Basically materials used in the Karnali cable stayed bridge are Structural steel, concrete and steel cable. The material constants are listed on Table 1. Initial strain on each cable was assigned to match the design cable tension. Stay cables of Karnali Bridge are composed of helically wounded steel strands of $7 \mathrm{~mm}$ diameter. Details of the cables are given in Appendix I. Stay cables of Karnali Bridge are constructed using combination of $7 \mathrm{~mm}$ diameter steel strands ranging from 55 to 199 in each cables.

Table 1: Material Properties

\begin{tabular}{|c|c|c|c|c|}
\hline S. N. & Structural Member & Young's Modulus $(\mathrm{Mpa})$ & Density $\left(\mathrm{Kg} / \mathrm{m}^{3}\right)$ & Poisson's ratio \\
\hline 1 & Stay Cables & $2.1 \times 10^{5}$ & 7850 & 0.3 \\
\hline 2 & Structural Steel & $2.1 \times 10^{5}$ & 7850 & 0.3 \\
\hline 3 & Floor Beams & $2.1 \times 10^{5}$ & 7850 & 0.3 \\
\hline 4 & Tower Steel & $2.1 \times 10^{5}$ & 7850 & 0.3 \\
\hline 5 & Deck concrete & $3.25 \times 10^{4}$ & 2400 & 0.15 \\
\hline
\end{tabular}

\section{Static Analysis Dead Load}

Dead load is often dominant feature on a long span cable stayed bridge. The pre-strain on the stay cable controls the internal force distribution in the deck and tower as well as the bridge alignment. The initial deformed equilibrium configuration of the bridge is important since it is the starting position to perform the succeeding Modal and Time history analysis. It is realized by manipulating the initial tension force in each stay cable. The cable tension is adjusted until the best match between calculated deck alignment and measured deck alignment is achieved. Achieving the deformed equilibrium configuration due to dead load is indeed one of the most difficult tasks involving multiple trial and errors. Difference between the calculated cable tension and the design cable tension is found to be below $21.5 \%$ ( See Appendix I). 


\section{Deformed equilibrium configuration with and without considering large displacement}

To analyze the importance of the large displacement consideration to achieve the dead load deformed equilibrium configuration due to the dead loads, responses of the bridge considering the large displacement and without considering large displacement (small strain, P-delta effects considered) are compared. Table 2 shows that large displacement geometric nonlinearity has little influence on the response behavior and small strain analysis is adequate as suggested by previous investigator.

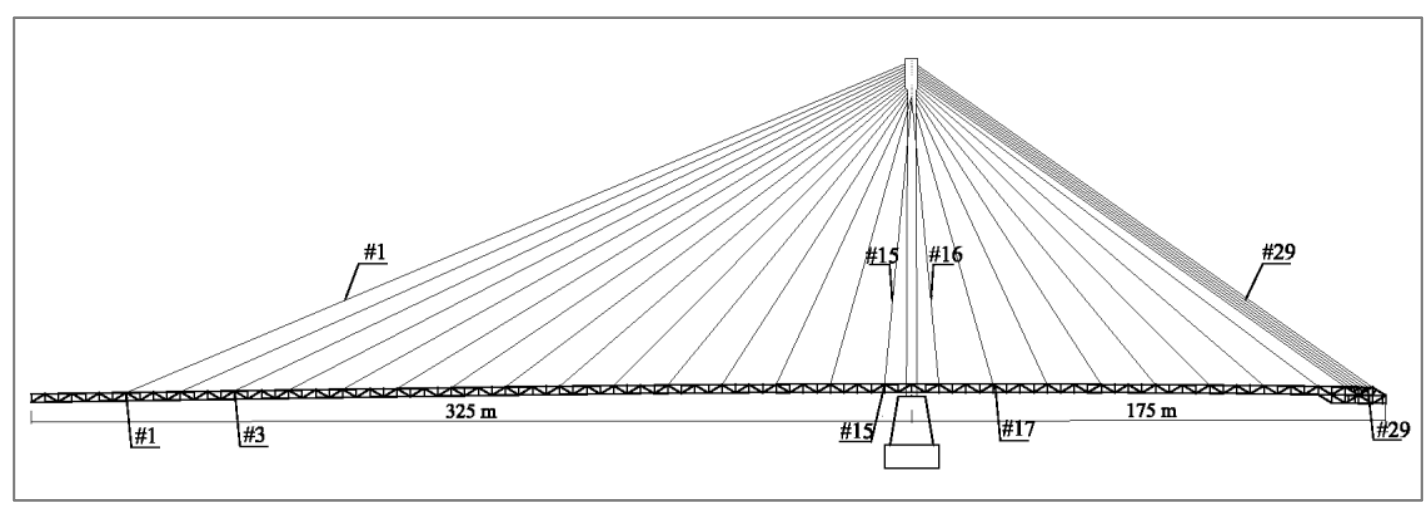

Figure 2: Elevation of Karnali Cable-stayed Bridge

Table 2: Vertical displacement under dead load

\begin{tabular}{|c|c|c|c|}
\hline \multirow{2}{*}{ Joint } & Small strain analysis & Large displacement analysis & $\%$ Diff. \\
\cline { 2 - 4 } & Ver. Displacement $(\mathrm{m})$ & Ver. Displacement $(\mathrm{m})$ & \\
\hline 1 & 0.030902 & 0.030855 & -0.15 \\
\hline 3 & 0.035092 & 0.035047 & -0.13 \\
\hline 5 & 0.042979 & 0.042857 & -0.28 \\
\hline 7 & 0.02274 & 0.022598 & -0.63 \\
\hline 9 & 0.005513 & 0.005423 & -1.66 \\
\hline 11 & 0.014674 & 0.014606 & -0.47 \\
\hline 13 & 0.019597 & 0.019553 & -0.23 \\
\hline 15 & -0.024762 & -0.024771 & 0.04 \\
\hline 17 & -0.014198 & -0.014177 & -0.15 \\
\hline 19 & -0.025458 & -0.025405 & -0.21 \\
\hline 21 & -0.048765 & -0.048772 & 0.01 \\
\hline 23 & -0.067193 & -0.067245 & 0.08 \\
\hline 25 & -0.029772 & -0.029814 & 0.14 \\
\hline 27 & -0.006789 & -0.00682 & 0.45 \\
\hline 29 & -0.004885 & -0.00494 & 1.11 \\
\hline
\end{tabular}




\section{Modal Analysis}

Natural response, also referred to as free vibration, is the response of a structure when disturbed from its static equilibrium position by an initial displacement or velocity and then allowed to vibrate without any external excitation. The mode shapes are useful in developing an understanding of the behavior of the structure. To investigate the effect of the cable discretization on the dynamic behavior of the bridge the modal analysis of the bridge is accomplished by modeling each cable as Single and six elements respectively.

\section{Classification of vibration modes}

The first 600 modes of the cable stayed bridge are carried out with Single cable element model (1ECM) with the highest frequency of $50.8 \mathrm{~Hz}$. Modal mass participation achieved with 600 modes were above $90 \%$ in $\mathrm{X}$ and $\mathrm{Y}$ direction, however in vertical direction modal mass participation was just $88 \%$. Most global modes are three-dimensional and have coupled modal components in different directions. Undoubtedly, the modes are very difficult to separate when they are sufficiently coupled. There are strong coupled modes (like bending and torsion) in the three orthogonal directions. Cables vibration modes were not captured by the 1ECM. Hence further refinement on the modal was done using six element cable model (6ECM). Using 6ECM, fundamental vibration period of each cable was calculated. Here, based on the dominant modal component, the vibration modes of the Karnali cable-stayed bridge are classified into four categories:

1) Deck lateral bending and torsion modes

2) Deck vertical bending mode

3) Cable local modes

4) Tower and pier dominated modes

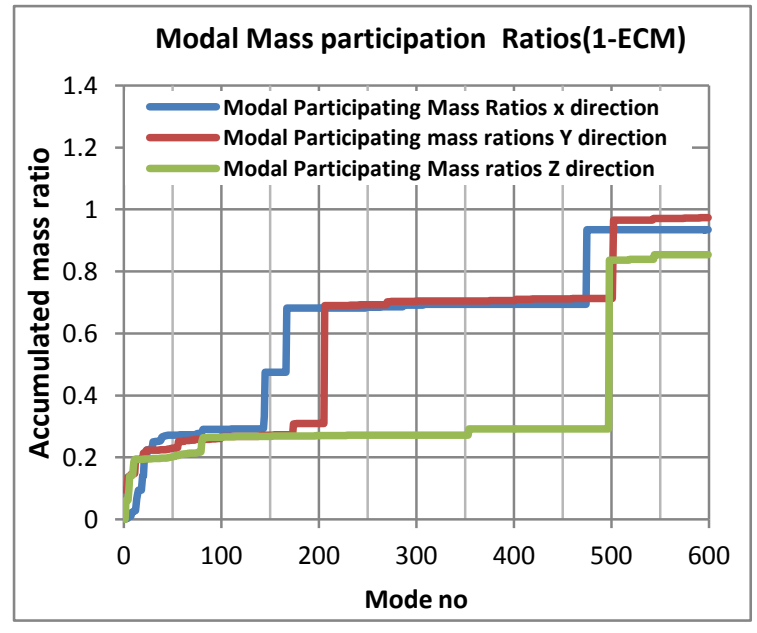

Figure 3: Modal mass participation in each direction

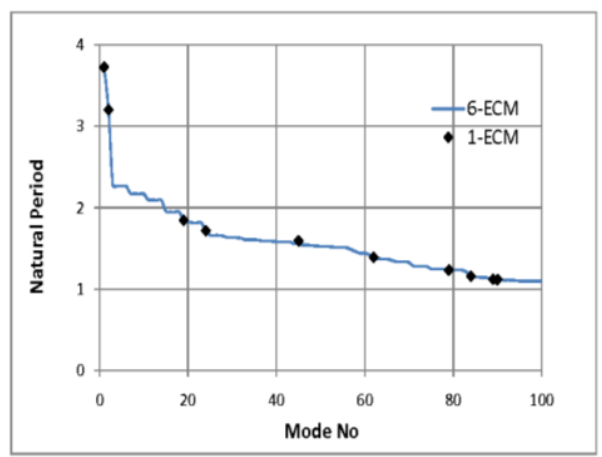

Figure 4: Mode distribution with 1ECM and $6 \mathrm{ECM}$

Figure 2 presents the modal mass participation for each direction. Modal mass participation increases rapidly with the inclusion of the Pier modes. Table 2 shows the comparison of global 
modes with 1ECM and 6ECM. Even though, multiple modes are introduced due to the inclusion of the cable local vibration into the model. This does not have significant impact on the global modal periods.

Table 3: Comparison of Natural Period

\begin{tabular}{|c|c|c|c|c|c|}
\hline \multirow{2}{*}{\begin{tabular}{c}
\multirow{2}{*}{$\begin{array}{c}\text { order } \\
\text { no. }\end{array}$} \\
\cline { 2 - 5 }
\end{tabular}} & \multicolumn{4}{|c|}{1 -ECM } & \multicolumn{2}{|c|}{6 -ECM } & \multirow{2}{*}{ Error \% } \\
\cline { 2 - 5 } & Period & Mode no. & Period & Mode no. & \\
\hline 1 & 3.7366 & 1 & 3.7258 & 1 & -0.29 \\
\hline 2 & 3.2207 & 2 & 3.2051 & 2 & -0.49 \\
\hline 3 & 1.8678 & 3 & 1.8494 & 19 & -1 \\
\hline 4 & 1.6655 & 4 & 1.7165 & 24 & 2.97 \\
\hline 5 & 1.5594 & 5 & 1.5926 & 45 & 1.55 \\
\hline 6 & 1.3974 & 6 & 1.3915 & 62 & -0.42 \\
\hline 7 & 1.2341 & 7 & 1.2344 & 79 & 0.03 \\
\hline 8 & 1.1616 & 8 & 1.1589 & 84 & -0.23 \\
\hline 9 & 1.1331 & 9 & 1.1231 & 89 & -0.89 \\
\hline 10 & 1.1169 & 10 & 1.1168 & 90 & 0 \\
\hline
\end{tabular}

\section{Parametric studies}

One of the major advantages of using Finite element modeling and analysis is to make different possible parametric study. The study undertaken here not only demonstrates the flexibility and efficiency of finite element model, but also demonstrates the extent and nature of vibration in modal properties that a variation in input parameters can cause. To identify the significance of deck concrete on overall dynamic behavior parametric study was conducted. To simulate the variation of the deck stiffness Elastic modulus of deck concrete was varied to find out its significance on various mode shapes. Modulus of elasticity of deck concrete is dealt in relative term where, unity represents the modulus of elasticity of $32500 \mathrm{~N} / \mathrm{mm}^{2}$. Fig 4, 5, 6 and 7 represents the variation in modal period on torsional, transverse, vertical as well as coupled transverse and torsion mode respectively.

It is observed that, the modulus of elasticity of the Deck concrete is key parameter affecting the torsional and transverse deck modal properties. It is seen that generally due to the loss of modulus of elasticity of concrete the flexibility of the structure is increased due to reduction in stiffness especially in transverse and torsional modes of the vibration. The loss of modulus of elasticity of deck concrete does also affect the vertical deck modes but its magnitude is small compared to the transverse and torsional responses. From the presented evidence it could be concluded that mistreatment of deck concrete may lead to the errors and the trend of neglecting the deck concrete with lumped mass applied at joints of the deck frame is misleading. 


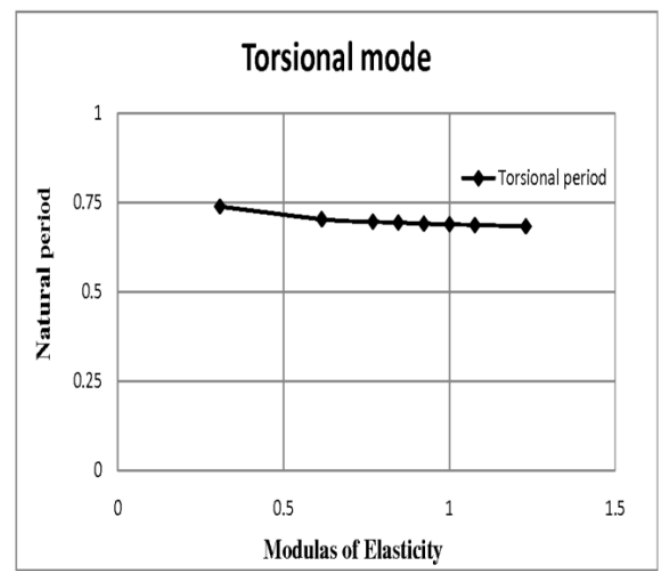

Figure 5: Variation in natural period of Torsional mode

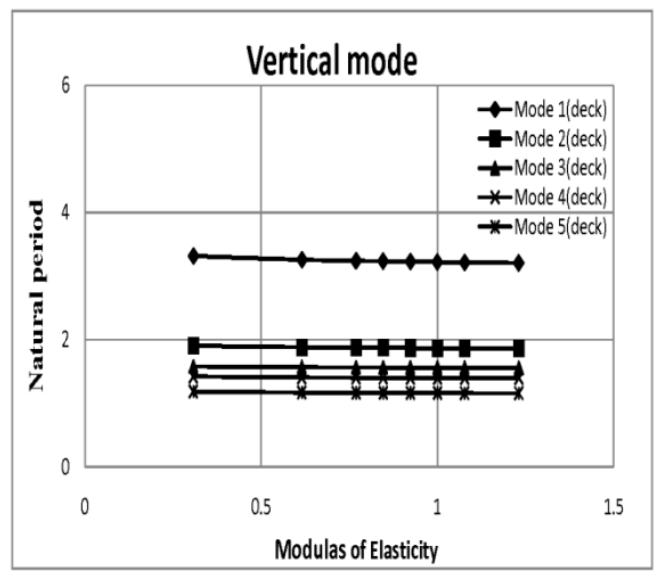

Figure 7: Variation in natural period of Vertical mode

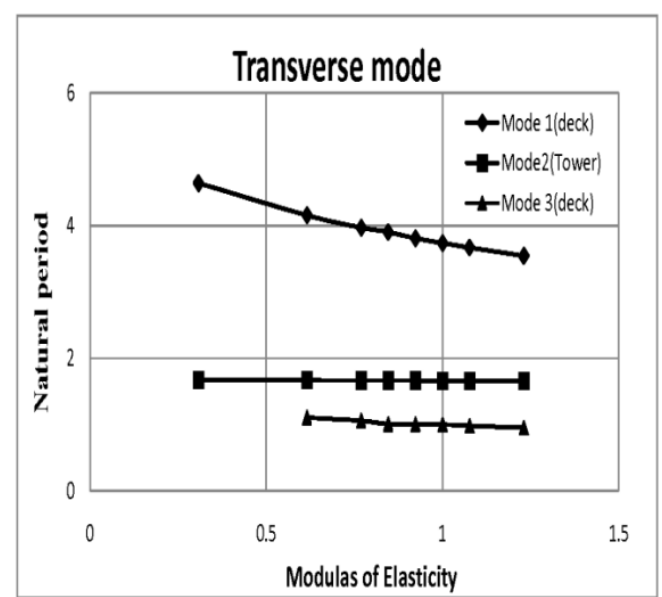

Figure 6: Variation in natural period of Transverse mode

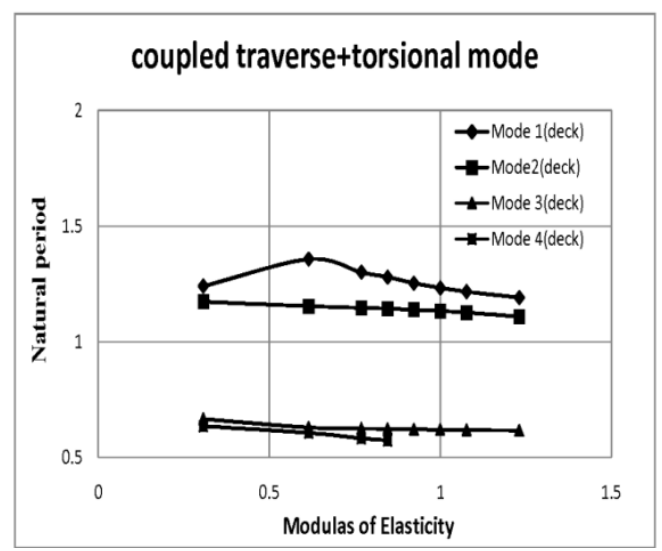

Figure 8: Variation in natural period of Coupled transverse + torsional mode

\section{Conclusions}

A Full three dimensional model was developed for the Karnali cable stayed bridge. From the series of the studies including the dead load static analysis, the modal analysis and the parametric studies, following conclusions can be made:

- The simple beam element (spine) models of the bridge deck cannot effectively represent the three-dimensional vibration behavior of cable-stayed bridges.

- The initial equilibrium configuration of cable-stayed bridge is important since it is the starting position from which to perform the succeeding dynamic analysis. The modal analysis of cable-stayed bridges and succeeding dynamic analysis under earthquakes, winds and vehicles involves two steps: the static analysis due to the dead load and cable tensions, and the subsequent dynamic analysis. 
- The initial equilibrium configuration of a cable-stayed bridge can be adequately achieved by small deflection static analysis.

- Cables local vibration modes cannot be captured by single element cable model. Multiple element cable model is hence needed to capture the cable local vibration modes. Use of multiple cable element model (6ECM) introduces multiple cable local modes which increases the numbers of modes to be observed. However, it has no significant impact on the global modal periods of the bridge.

- The vibration modes of the Karnali Bridge can be classified in four categories: a. Deck lateral bending and torsion modes b. Deck vertical bending mode, c. Cable local modes and $\mathrm{d}$. Tower and pier dominated modes.

- Through the parametric study, it is concluded mistreatment with deck concrete can have significant impact on the torsional and transverse deck modal properties. The practice of neglecting the stiffness of deck concrete by introducing the lumped mass at joints could significantly alter the dynamic behavior of the bridge.

\section{Acknowledgements}

The Author wishes to acknowledge the contribution of Dr. Roshan Tuladhar and Mr. Jagat Kumar Shrestha, Lecturers at Institute of Engineer for their contribution as thesis supervisor of the author.

\section{References}

[1] Fleming, J. F., and Egeseli, E. A. (1980). Dynamic behavior of a cable-stayed bridge, Earthquake Engg Struct Dyn, 8(1):1-16.

[2] Nazmy, A.S., and Abdel-Ghaffar, A.M. (1990). Nonlinear earthquake response analysis of long-span cable-stayed bridges: applications, Earthquake Engrg Struct Dyn, 19(1):63-76.

[3] Wilson, J.C., and Gravelle, W. (1991). Modeling of a cable-stayed bridge for dynamic analysis, Earthquake Engg Struct Dyn , 20(8):707-721.

[4] Cunha, A., Caetano, E., and Delgado, R. (2001). Dynamic tests on large cable-stayed bridge, J Bridge Engrg, ASCE, 6(1):54-62.

[5] Ren, W. X., and Peng, X. L. (2005), Baseline finite element modeling of a large span cable-stayed bridge through field ambient vibration tests, Com and Struct 83(17), 536-550.

[6] Ren, W.X., Blanford, G. E., and Harik, I. E. (2004). Roebling suspension bridge. I: Finite element model and free vibration response, Jour. of Bridge eng. 9(2), 110-118.

[7] Wilson, E. L. (2002). Three-dimensional static and dynamic analysis of structures: a physical approach with emphasis on Earthquake Engineering, Com. and Struct Inc., 2002.

[8] Ni, Y.Q., Wang, J.Y. and Ko, J.M. (2000). Modal Interaction in Cable-Stayed Ting Kau Bridge, Proc of the Int Conference on Advances in Struct Dyn, Hong Kong.

[9] Shrestha B. (2009). Effects of near field vertical acceleration on seismic response of long span cablestayed bridge, MSc thesis, IOE Pulchowk Campus, Tribhuwan University.

[10] Hu, J., Harik, I. E., Smith, I. W., Gagel, J., Campbell, J.E., and Graves, R.C. (2006). Baseline Modeling of the Owensboro Cable-stayed Bridge over the Ohio River. Research Report, KTC. 
Appendix I: Cable Stays Composition of Karnali Bridge

\begin{tabular}{|c|c|c|c|c|c|c|}
\hline Cable & $\begin{array}{c}\text { No. of } \\
\text { 7mm Wires } \\
\text { in each } \\
\text { Cable }\end{array}$ & $\begin{array}{c}\text { Area of } \\
\text { Wire } \\
\left(\mathrm{mm}^{2}\right)\end{array}$ & $\begin{array}{c}\text { Horizontal } \\
\text { projected } \\
\text { length(m) }\end{array}$ & $\begin{array}{c}\text { Design } \\
\text { Cable } \\
\text { tension (Kn) }\end{array}$ & $\begin{array}{c}\text { Computed } \\
\text { Cable } \\
\text { tension (Kn) }\end{array}$ & $\begin{array}{c}\text { Percentage } \\
\text { Diff }\end{array}$ \\
\hline 1 & 163 & 6273 & 290 & 4069 & 3775 & 7.23 \\
\hline 2 & 109 & 4195 & 270 & 2601 & 2432 & 6.48 \\
\hline 3 & 109 & 4195 & 250 & 2468 & 2248 & 8.92 \\
\hline 4 & 109 & 4195 & 230 & 2410 & 1998 & 17.11 \\
\hline 5 & 109 & 4195 & 210 & 2151 & 1996 & 7.22 \\
\hline 6 & 109 & 4195 & 190 & 2094 & 1967 & 6.08 \\
\hline 7 & 85 & 3271 & 170 & 1693 & 1554 & 8.22 \\
\hline 8 & 85 & 3271 & 150 & 1770 & 1568 & 11.4 \\
\hline 9 & 73 & 2809 & 130 & 1530 & 1327 & 13.29 \\
\hline 10 & 73 & 2809 & 110 & 1504 & 1296 & 13.82 \\
\hline 11 & 61 & 2347 & 90 & 1298 & 1192 & 8.16 \\
\hline 12 & 55 & 2117 & 70 & 1162 & 970 & 16.49 \\
\hline 13 & 55 & 2117 & 50 & 1162 & 1000 & 13.98 \\
\hline 14 & 55 & 2117 & 30 & 1047 & 1020 & 2.55 \\
\hline 15 & 55 & 2117 & 10 & 1103 & 1007 & 8.67 \\
\hline 16 & 55 & 2117 & 10 & 1116 & 1102 & 1.29 \\
\hline 17 & 55 & 2117 & 30 & 1000 & 1052 & -5.24 \\
\hline 18 & 55 & 2117 & 50 & 1063 & 982 & 7.66 \\
\hline 19 & 55 & 2117 & 70 & 1134 & 930 & 17.99 \\
\hline 20 & 61 & 2347 & 90 & 1275 & 1206 & 5.43 \\
\hline 21 & 73 & 2809 & 110 & 1358 & 1334 & 1.75 \\
\hline 22 & 73 & 2809 & 130 & 1587 & 1644 & -3.57 \\
\hline 23 & 85 & 3271 & 150 & 1728 & 1969 & -13.98 \\
\hline 24 & 85 & 3271 & 160 & 1832 & 1438 & 21.49 \\
\hline 25 & 109 & 4195 & 161.67 & 2373 & 1902 & 19.85 \\
\hline 26 & 109 & 4195 & 163.33 & 2381 & 2010 & 15.58 \\
\hline 27 & 127 & 4887 & 165 & 2633 & 2526 & 4.06 \\
\hline 28 & 127 & 4887 & 166.67 & 2749 & 2547 & 7.34 \\
\hline 29 & 151 & 5811 & 168.33 & 2964 & 2756 & 7.01 \\
\hline 30 & 199 & 7658 & 170 & 4467 & 3528 & 21.03 \\
\hline
\end{tabular}

